\title{
The Pragmatic and Dialectical Dynamics of an Illegitimate Argument
}

\section{ScotT JACOBS}

Department of Communication

University of Arizona

Tucson, AZ 85721 U.S.A.

jacobsc@u.arizona.edu

There is much that is objectionable and suspect in Shell's magazine advertorial, "Clear Thinking in Troubled Times." This essay will focus in particular on the argument put forward in the three paragraphs (8-10) from lines 37 through 54 , and will use Tindale's (1999) assessment of those arguments as a platform for launching my own evaluation and analysis. I want to elaborate two general points about the nature of argument quality and argument evaluation.

First, like Tindale, I believe that argument analysis and evaluation must take into account the audience in the argumentation process and must acknowledge that arguments are characteristically (if not always) less than certain demonstrations of the claims they support. The construction of arguments is a bilateral process, whether thought of rhetorically in the roles of a speaker and an audience or dialectically in the roles of two interlocutors. And it is most useful to think of those arguments as stronger or weaker, as more or less convincing, rather than as certain or worthless. But it seems to me that two straightforward implications of these ideas is that the stance from which an audience (or critic) receives an argument can be questioned and evaluated and that any argument evaluation is itself essentially controversial, having the same sorts of properties as the arguments the critic evaluates.

Second, we can examine our intuitions about argument quality to uncover the interpretive structuring of argument. Arguments exist as messages. Their content, function, and form are all constructed according to interpretive principles. Not much attention has been given to these principles (though see van Eemeren \& Grootendorst, 1982a, 1982b, 1984, 1992, or Jacobs, 1995, 1999). But these principles are just as crucial to the organization and quality of arguments as are the principles of inference that logicians have studied or the principles of engagement that rhetoricians and dialecticians have articulated. And these principles can be articulated by "working back" as it were from our evaluative intuitions.

Both of these points can be shown by examining the passage from the Shell advertorial. In paragraphs 8,9 , and 10 , two claims are implicitly put forward in 
opposition to courses of action called for by critics of Shell:

Claim 1: Shell should not pull out of Nigeria's Liquified Natural Gas Project. (lines 37-38)

Clalm 2: Shell should not pull out of Nigeria altogether.

(lines 48-49)

These two claims are defended by more or less parallel lines of argument whose main reasons consist of the following:

REASON 1: If Shell pulls out, the Nigerian people will be hurt.

(lines $41-43$; 52-54)

REASON 2: If Shell pulls out, the environment will be hurt. (lines 43-44; 50-52)

REASON 3: If Shell pulls out, only the future Nigerian government will be hurt; and not the current government.

(lines $44-47 ; 48-50$ )

Notice that the two claims and their supporting arguments work in such a way that if Claim 1 is redeemed, then CLAim 2 also follows, at least to some extent.

I think we have good reason to think that this is a bad argument-or, more accurately, we have good reason to be suspicious of this argument. But the problem resides in more than just the suspicion that the reasons offered are false or dubious; and in more than just the suspicion that the reasoning is not strong enough to counterbalance competing considerations for why Shell should pull out. Suspicions of this kind may or may not ultimately prove to be well founded. Only further debate could really pin that question down. Unfortunately, argument assessment too frequently stops here as a way of redeeming an intuition that there is something suspect about an argument.

There is, however, a more fundamental and subtle source of trouble with this argument that I think that many people vaguely perceive. I want to try to articulate and redeem the intuitions that alert us to this suspicious trouble. I don't think that the trouble is so overt and obvious as to count as a clear-cut, accomplished fallacy. It is more like a potential fallacy, a virtual trouble. I believe that what can be seen in this passage is an abuse of sorts, a kind of failure to argue in good faith. At work here are some interesting principles of rational deliberation and message interpretation.

To get at what I think is troubling about this passage, it is useful to start with what Tindale (1999) says about the passage. He shares my intuition that there is something wrong here. But I don't think that he has it right about what it is exactly that has gone wrong in this passage. Tindale raises three objections. The first two objections parallel those of the type I have just alluded to above, and I don't think they amount to really telling criticisms. His third objection is more interesting, and I think it sets us in the right direction toward pinning down exactly what is suspect about this argument. 
Tindale's first objection is that Shell does not prove the premises in their reasoning:

It has the form of a Slippery Slope: if Shell pulls out of the project, the project will collapse. And from this will follow harm to the Nigerians, to the environment, and to the future government and peoples. A similar consequence is anticipated for the more general removal from Nigeria. What reasons do we have for believing these effects will follow, and that they would be as devastating as claimed if they were to transpire? The key statement is [that if Shell pulls out of the project, the project will collapse]. Will the project collapse without Shell's involvement? Or will it be modified or reduced? (pp. 143-144; italics added and notation deleted)

This objection doesn't strike me as drawing real blood. There is nothing intrinsically wrong with a slippery slope argument. It can often be used quite legitimately (Walton, 1992). Tindale's objection is the sort of skeptical challenge you raise when you don't agree with the claim being defended and you don't find the argument so compelling as to force assent. Tindale's questions don't prove anything, and his skepticism amounts to a kind of ad ignorantiam criticism that has force only by presuming in the first place that there is something fishy about Shell's argument. It may in fact be the case, as Tindale suspects, that the adverse consequences anticipated by Shell are overstatements or outright falsehoods, but Tindale gives no positive reason to suppose this is so. Any argument could be subjected to this kind of criticism since all arguments must be based at some point on unsupported premises. The real question is whether or not there is any positive basis for doubting these premises. Audience skepticism can be reasonable or unreasonable, and audiences must take responsibility for adopting a reasonable level of skepticism.

To say that an arguer is dialectically obligated to provide the kind of proof Tindale calls for really confuses what it would take to persuade an entrenched opponent who has a built-in bias against your position with what it would take to put forward a prima facie case, or at least, to put forward a plausible rationale for maintaining a standpoint. Tindale may well be correct in assuming that Shell's argument would not convince many who suggest that Shell should pull out of Nigeria's Liquified Natural Gas Project or pull out altogether. But while the starting premises of this argument might not be ones that Tindale's projected audience would accept, that does not mean they should not. This failure hardly supports the conclusion that Shell has "argued illegitimately" (Tindale's term, p. 144).

Tindale's second objection to this passage is that Shell's arguments overlook the political benefit to the Nigerian government of the Liquified Natural Gas Project and so fail to weigh the overall harms and benefits of pulling out or staying in:

Dialectically, this [reasoning in lines 41 through 47] overlooks some serious counterargumentation: that the current regime stands to gain considerable status just by having the project go ahead. (p. 134)

[T] he claim that the current regime will not profit from the project considers only the direct financial relationship and overlooks how such a project con- 
fers status on a government and, in serving as an example of a substantial international investment, opens the door for other investments from which the government might profit. Thus, there is a key counterargument to be raised against the arguer's point. (p. 137)

This omission violates the principle that "an arguer is obliged to acknowledge the more obvious counterargumentative moves likely to be brought against a thesis" (p. 137).

Even if we ignore the way that the first objection Tindale skeptically raises against Shell's argument could just as well be leveled against his own reasoning here (notice that Tindale raises arguments that a Shell supporter might ask him to prove), this kind of objection still doesn't really show that Shell has "argued illegitimately". Grant for the moment that Tindale has legitimate reason to think he knows what he is talking about with respect to the socio-political dynamics of international investment in Nigeria; presumably, the skeptical audience with which Tindale identifies would also be aware of this counterargument. Shell's argument doesn't suppress this consideration; it simply creates the conditions for judging the relative weight of the arguments for and against, without showing exactly how to do so.

Surely Shell's argument would be stronger had this counterargument been directly refuted; but recognizing that a one-sided argument is weaker than it could be is not the same as declaring it "illegitimate." If anything, the argument is less likely to be persuasive because it fails to draw the balance and explicitly refute the objection (O'Keefe, 2002:219-221). But if this makes the argument illegitimate, it is the peculiar sort of illegitimacy where an arguer presents good reasons for accepting a claim but presents them unpersuasively. It is the other way around that we usually have in mind when we brand an argument as illegitimate.

So neither of Tindale's first two objections find much traction. They simply point to the fact that the reasons Shell offers for not pulling out of Nigeria or its Liquid Natural Gas Project do not have the weight of decisive, knockdown arguments that conclusively decide the matter. As Tindale puts it: "While the likelihood of some harm is reasonable to believe, we cannot be sure the effects would be as devastating as claimed. Nor, more importantly, can we be sure that Shell's continued presence, given the implicit support it would give to the government, would be less harmful than its withdrawal" (p. 144; italics added). Tindale's first two objections do not demonstrate that Shell has somehow argued illegitimately. At best, they only show that one could reasonably remain unconvinced of Shell's position. At worst, Tindale's first two objections exploit a kind of audience bias that ought to be questioned. It is common for people to overlook faults in the arguments of positions they agree with and to find faults in the arguments of positions with which they disagree (Jackson, 1996). If measured charity is reasonable, then unmeasured skepticism is not. Audiences are just as responsible for the quality of the argumentation process as are arguers. Of course, what is and is not an appro- 
priate level of skepticism or benefit of the doubt is subject to debate. And it is a kind of debate that argumentation critics should more often consider.

Tindale's third criticism of the Shell argument is a more interesting one: He objects that "no reference is made of the harm that would result for the company itself and for its investors" (p. 133).

The most serious omissions were identified in Paragraph 9 [lines 41-47, ed.] When the arguers detail the harms that would result from Shell canceling the natural gas project, they omit any reference to the negative impact it would have on the company itself. It is not only the people and government of the future Nigeria who would be harmed, one might object, but Shell will lose its substantial investment in the project as well as even greater future revenues. In the context of the international debate, oil company profits have been a prominent topic and the arguers would be wiser to address it than to ignore it. (p. 137)

Tindale reports that Shell has a "\$3.6-billion investment" in the Liquid Natural Gas Project (p. 133). In other words, Shell has a strong profit motive for not pulling out of Nigeria or its Liquified Natural Gas Project. One strongly suspects that this is the real reason why Shell does not want to pull out, and not because of the prosocial concerns raised in lines 37-54.

But what does this objection really amount to? Intuitively, it seems to raise a serious problem. I do think that this kind of problem hangs in the back of the mind of a reasonably skeptical interlocutor, but if you look at it closely the objection doesn't really disprove anything argued by Shell. The fact that Shell has a strong profit motive for not pulling out certainly does not show that Shell should pull out of Nigeria altogether or out of its Liquified Natural Gas Project. If anything, this fact shows just the opposite. It provides further reason for exactly what Shell is claiming: that they should not pull out of Nigeria altogether or pull out its Liquified Natural Gas Project. Nor is it in any way obvious how pointing out that Shell has a strong profit motive to stay in Nigeria disproves any of the reasoning for Shell's claims. Arguing that Shell has a motive not to pull out because it would be financially hurt in no way denies that the people, the environment or the future government of Nigeria would be hurt as well. Even as an indirect undermining of the credibility of Shell's arguments, it is not clear how far this objection takes us.

In fact, this objection looks just like a classic motivational ad hominem attack-something most argumentation theorists would dismiss as a fallacy. The problem with using motivational ad hominem arguments to object to a position is that one's motives for making an argument have no direct bearing on the quality of that argument. One can argue with complete sincerity and out of the best of motives and still make arguments that are weak or fallacious. And one can be quite indifferent or even cynical about one's arguments and still make good ones. Science and the law both require in their own ways recognition of a separation of Arguer and Argument. Profit motive, in particular, is something that by itself carries no weight in legal or scientific deliberations. We don't even think of it as 
insincerity or bad faith when arguers willingly put their claims at risk by submitting them to judgment according to publicly defensible reasons.

And it is unlikely that the problem Tindale raises by this objection is that Shell has failed to acknowledge and refute a fallacious attack on their credibility. There are certainly cases where it would be prudent for arguers to acknowledge and refute audience objections which keep that audience from adopting the advocated position even when those objections amount to fallacies (though it is hard to see how failure to anticipate and answer fallacies could render the arguments that are made "illegitimate"). But Tindale doesn't seem to regard his objection as raising a fallacy at all. He seems to regard it as having some legitimate force of its own. But what, exactly, is the nature of the trouble this objection raises?

I think the trouble has to do with the suspicion that Shell is not really putting their claims at risk. The suspicion is that Shell is committing a kind of virtual fallacy - they haven't done it yet, but they will if they have to. To see this, you have to see two principles at work. The first at work is a pragmatic principle that leads to a kind of implicature, an inference that is not logically necessary, but is warranted in ordinary circumstances (Davis, 1998; Grice, 1989). The second is a dialectical rule of reasonable procedure.

First, the pragmatic principle. Shell's pro-social arguments invite readers to infer that these reasons are held by the arguer to be the reasons for holding the standpoint that Shell should not pull out. We feel like this inference has been defeated when we are told that Shell has a $\$ 3.6$ billion motive not to pull out. We feel like that fact should have been disclosed since it would appear to be an even more important reason (at least to Shell) for not pulling out of the Liquified Natural Gas Project. I would suggest that what is going on here is the application of the following pragmatic principle of communication:

In the absence of contra-indications, when an arguer puts forward a reason for accepting a claim, the arguer is putting forward what they take to be the best reasons for accepting that claim.

This principle works in such a way that when an arguer puts forward a reason, and gives no indication that there are other reasons to consider, audiences are warranted in making the inference that the arguer takes that reason to be the reason for accepting a claim. And the more reasons put forward, the stronger our confidence that the arguer has put forward the best reasons. As a pragmatic principle, the inferences generated are conversational implicatures in the sense that Grice (1989) discusses. They can be cancelled by counterbalancing indications. For example, special circumstances may defeat the inference. When issued as a response to a particular objection, one might assume that the reason offered is not in general the best or only reason but the one most relevant to the objection raised. In the back and forth of fast paced conversational debates where speakers have limited time and access to the floor, this principle may be weakened. And there are ways in which arguers may frame their reasons so as to cancel this implicature. 
For example, had Shell said, "While we have our own reasons for not pulling out, these are ones that you should find compelling," or "There are many reasons not to pull out of the project, but consider this ..." we would be much less likely to think that Shell was deliberately hiding a profit motive. But they don't offer such framing, and there is nothing special about the circumstances of this advertorial that would cancel the ordinary interpretation of their argument.

Second, the dialectical principle. As van Eemeren and Grootendorst (1984, 1992) have argued, reasonable discussion proceeds according to a rule that if a standpoint is not adequately defended, it must be withdrawn and it may be reasserted only by new arguments. So, in the case of Shell's argument, if the prosocial reasons for not pulling out of Nigeria or its Liquified Natural Gas Project were to be defeated, Shell would have to abandon its standpoint. After all, they have implicated that these pro-social reasons are the reasons they hold the standpoint in the first place. There are no other good reasons for maintaining the standpoint. And here is where I think skeptical readers project the virtual fallacy. Do critics really think that Shell would abandon their position? Maybe they would. Reasonable arguers would do so when they do not have reasons that they are willing and able to publicly defend. But what the skeptic anticipates is that Shell would just come up with another argument for not pulling out. Or they would simply refuse to admit defeat of their standpoint and reasoning. This is the pattern of disingenuous, bad faith arguing that everyone has some familiarity with and finds so exasperating. Now, admittedly, Shell has put forward their three reasons for not pulling out because they think they are making winning arguments. One suspects that they have exploited the situation so as to maneuver into a no-lose situation.

So, it is this kind of strategic maneuvering (van Eemeren \& Houtlosser, 2002) that I think really underlies the intuition that Shell is arguing illegitimately-or more accurately, may come to be arguing illegitimately. For the abuse is merely in the offing; it is a virtual offense of reasonable procedure that may not actually come about. This maneuver is the result of exploiting a combination of pragmatic principles of communication and dialectical principles of procedure. And it is in seeing these principles at work in this case that we can redeem our intuitions concerning argument quality.

\section{References}

Davis, W, A. (1998). Implicature: Intention, Convention, and Principle in the Failure of Gricean Theory. Cambridge, UK: Cambridge University Press.

Eemeren, F. H. van, \& Grootendorst, R. (1982a). Unexpressed premises: Part I. Journal of the American Forensic Association, 19, 97-106.

Eemeren, F. H. van, \& Grootendorst, R. (1982b). Unexpressed premises: Part II. Journal of the American Forensic Association, 19, 215-225. 
Eemeren, F. H. van, \& Grootendorst, R. (1984). Speech Acts in Argumentative Discussions: A Theoretical Model for the Analysis of Discussions Directed Towards Solving Conflicts of Opinion. Dordrecht, Holland: Foris.

Eemeren, F. H. van, \& Grootendorst, R. (1992). Argumentation, Communication, and Fallacies: A Pragma-Dialectical Perspective. Hillsdale, NJ: Lawrence Erlbaum Associates.

Eemeren, F. H. van, \& Houtlosser, P. (2002). Strategic maneuvering: Maintaining a delicate balance. In F. H. van Eemeren \& P. Houtlosser (Eds.), Dialectic and Rhetoric: The Warp and Woof of Argumentation Analysis (pp. 131-159). Dordrecht, Holland: Kluwer Academic Publishers.

Grice, H. P. (1989). Studies in the Way of Words. Cambridge, MA: Harvard University Press.

Jackson, S. (1996). Fallacies and heuristics. In J. van Bentham, F. H. van Eemeren, R. Grootendorst \& F. Veltman (Eds.), Logic and Argumentation (pp. 101-1 I4). Amsterdam, Holland: Royal Netherlands Academy of Arts and Sciences.

Jacobs, S. (1995). Implicatures and deception in the arguments of commercial advertising. In F. H. van Eemeren, R. Grootendorst, J. A. Blair, \& C. A. Willard (Eds.), Special fields and cases: Proceedings of the third ISSA conference on argumentation, vol. IV (pp. 579-592). Amsterdam: International Centre for the Study of Argumentation (SICSAT).

Jacobs, S. (1999). Argumentation as normative pragmatics. In F. H. van Eemeren, R. Grootendorst, J. A. Blair, \& C. A. Willard (Eds.), Proceedings of the Fourth ISSA Conference on Argumentation (pp. 397-403). Amsterdam: International Centre for the Study of Argumentation (SICSAT).

O'Keefe, Daniel J. (2002). Persuasion: Theory and Research, $2^{\text {nd }}$ ed., Sage: Thousand Oaks, CA.

Tindale, C. W. (1999). Acts of Arguing: A Rhetorical Model of Argument. Albany, NY: State University of New York Press.

Walton, D. (1992). Slippery Slope Arguments. Oxford, UK: Clarendon Press. 